\title{
SEISMIC RISK PERCEPTION IN PRIMARY SCHOOL EDUCATION: A CASE STUDY
}

\author{
Ana Marques ${ }^{1}$, António Almeida ${ }^{2}$ \\ ${ }^{1}$ Centro Interdisciplinar de Estudos Educacionais (CIED) (PORTUGAL) \\ ${ }^{2}$ Instituto Politécnico de Lisboa (IPL) / Centro Interdisciplinar de Estudos Educacionais \\ (CIED) (PORTUGAL)
}

\begin{abstract}
In certain regions of the planet seismicity obeys the following pattern: medium to high seismic risk associated to major earthquakes with a long period of low seismicity. This is the case of Lisbon region where the last major earthquake was precisely the historic earthquake of Lisbon in 1755 . Since these extreme episodes have a pattern of periodicity of more than 200 years, seismic prevention is often ignored in Portuguese schools, in detriment of other more frequent risks, such as fires, floods or landslides.
\end{abstract}

Thus, a case study was developed in a Lisbon primary school with 25 pupils, aged between 7 and 9 years, attending the $3^{\text {rd }}$ year of schooling. The aims were: i) to identify pupils' knowledge about seismic risk; ii) to check how children assess the degree of seismic risk in the Lisbon region; (iii) to develop a safety culture through the approach of prevention measures and ways of acting in event of earthquake.

A questionnaire was administered with several questions about the seismic phenomenon, the degree of seismic risk in the Lisbon area and also about what to do before, during and after an earthquake. The questionnaire was scored as a test and administered in three stages: first an intervention plan with a set of sessions extended during one month related to the seismic phenomenon and including what to do in event of earthquake at school or at home (pre-test); after these sessions, at two different times: a week after the last session (post-test1); three months after this second administration (posttest2) to check learning persistence. The tests results were compared using the Wilcoxon ( $Z$ ) test, between pre-test and post-test1 and pre-test and post-test2.

The results showed a statistically significant improvement in pupils' knowledge of seismic phenomena, which persisted over time. Even so, the fact that in Lisbon several areas are more dangerous than others regarding seismic risk was not fully understood by the pupils, even after analysis of the geological map of the region. However, this may be related to the complexity of this approach, which may have led to several misunderstandings.

It is considered that this educational experience may highlight the need for inclusion of seismic risk in schools, especially in areas where the seismic pattern is as the one that was characterized above.

Keywords: Primary Education, risk Education, seismic risk, historic earthquakes.

\section{INTRODUCTION}

Risk is something inherent to Life, it is everywhere, and it can have diverse origins and equally distinct consequences. [1] Fischhoff \& Kadvany (2011) consider that we face risks in very different ways: using new technologies, during medicinal treatments, making personal economic investments, in familiar or social relationships, etc. Besides, everything we do involves some risk. But the sense of risk is often associated with disasters and catastrophes that may have a human or non-human origin. In this way, [2] Saúde et al. (2015) define risk as the occurrence of something involving danger with consequences for people, but which can also affect goods as well as the environment.

Therefore, if a phenomenon that causes damage originates in nature, it is called a natural risk; if the phenomenon originates in human actions, it is called a technological risk. When the phenomenon originates from the combined action of nature and human actions, it is called a mixed risk. Furthermore, [3] Wisner, Blaikie, Cannon, and Davis (2004) argue that "it is to risk separating "natural" disasters from the social frameworks that influence how hazards affect people, thereby putting too much emphasis on the natural hazards themselves, and not nearly enough on the surrounding social environment" (p. 4). 
Even knowing that less publicized events, like violent conflicts, illnesses, and hunger, can be greatest threats to humanity ([3] Wisner, Blaikie, Cannon, and Davis, 2004), natural disasters can have a strong negative impact on humans. That is why natural hazards are not irrelevant and our vulnerability to them is increasing ([4] Smolka, 2006). The reasons for this increase are related to World Population Growth, to the type of infrastructures and planning in urban areas and also to climate change due to global warming, just to mention a few ([5] Hill, Sparks, Rougier, 2013).

Risk, regardless of its natural, technological, or mixed origin, can be characterized in different ways: it may have has immediate or medium or long-term effects, it may be predictable or unpredictable, it may have more or less destructive effects, it may be more or less frequent, it may affect few individuals or large communities, it may have a different degree of inevitability and trigger more or less rational fears.

However, the real knowledge of a certain risk and the perception of it do not always coincide. Risk perception results from social representations, which are shaped by misconceptions, lack of information and / or the sense of control that we have or not about a certain risk ([6] Lima, 2008). The gap between the real danger of a particular risk and the perception we have of it has consequences at individual and social levels. And it generates a conception of danger which can exaggerate or minimize the danger that each risk actually represents.

The present study is focused on seismic risk, a risk that, according to [7] Geller, (1997), has distinctive features from other natural risks since it is totally unpredictable, and its consequences depend largely on the way the territory is planned and on the prevention actions that are developed within a given population to minimize it. [8] Axelrod, Mcdaniels \& Slovic (1999) consider earthquakes as the major natural risk faced by humans.

It is now known that an earthquake results from a violent fracturing inside the earth's crust, which releases a large amount of energy and causes vibrations that spread to a vast surrounding area ([2] Saúde et al., 2015). And the seismicity of the different regions of the planet is conditioned by its tectonic framing. In the case of Portugal, the territory is in the proximity of the limit between the EuroAsian plate and the African plate and is, apart from that, crossed by several active faults.

Portugal presents a moderate seismic activity, with the occurrence of large earthquakes in long seismic cycles ([9] Vila-Nova, 1997; [10] Borges, Fitas, Bezzeghoud, \& Teves-Costa, 2001). Generally, these earthquakes of great intensity occur in the south of the country, with a greater incidence in the regions of the Algarve and Lisbon ([11] Birkmann, Teichman, Welle, González \& Olabarrieta, 2011).

The record of the first seismic event in Lisbon dates from 718 ([12] Costa \& Fonseca, 2007). And [10] Borges et al. (2001) state that the city was affected by earthquakes of great magnitude in 1344 and 1531. But it was on 1 November 1755, All Saints' Day, that one of the most destructive earthquakes in the history of mankind happened, and which also became known as the Lisbon Earthquake. With the epicentre in the sea, this earthquake, with an estimated magnitude on the Richter scale of 8,5-9,0, caused damage in the cities of Lisbon and Setubal, and in the Algarve region, and in other coastal locations in Spain and Morocco ([13] Ribeiro, 2005; [11] Birkmann et al., 2011). In the case of Lisbon, there were estimated 70000 casualties, in addition to the numerous wounded and displaced persons ([13] Ribeiro, 2005). This calamity was also due to the tsunami generated by the earthquake and to the fire mainly caused by the candles burning in the churches, in the celebration of the religious day.

Even so, [6] Lima (2008) considers that people considered seismic risk less terrifying than other risks. This was also the conclusion reached by [14] Tavares, Mendes \& Basto (2011), in a recent study on the perception of the Portuguese population of natural and technological risks. Thus, the respondents' expectation of being hit by an earthquake of high magnitude was low, contrary to the history of occurrences of this natural risk. However, this low perception has a justification: since these extreme episodes have obeyed a pattern of periodicity of more than 200 years, the expectation of experiencing an earthquake with these features is low among the population. Moreover, the last seismic event in Lisbon with a destructive impact occurred in 1969 ([15] Téllez Alarcia, 2007), which means that a large part of the population has never witnessed an earthquake of high magnitude.

But the perception of low seismic risk among the population also results from the lack of information and the lack of attention to this risk given by school. Consequently, the low frequency of a certain risk is generally related to a tendency on the part of the local authorities and the population to forget the possibility of its occurrence ([11] Birkmann et al., 2011, p. 130). 
Therefore, risk education must be part of the curricula to better inform the population and to promote the development of a culture of security and resilience, as envisaged by the Hyogo Declaration ([16] United Nations, 2005). In this sense, school must be an intervention agent which disseminates relevant information and also encourages the active participation of the students. In other words, school must provide scientific knowledge about different risks and, at the same time, develop appropriate attitudes and behaviours for prevention and intervention, i.e., before, during and after their occurrence.

Thus, the present study had the following main goals:

1 To assess the knowledge about seismic risk in pupils of primary school;

2 To assess their perception of seismic risk, since the participants are pupils from a school in Lisbon;

3 To develop appropriate attitudes and behaviours before, during and after a seismic occurrence;

4 To develop a culture of security at school and at home.

\section{METHODOLOGY}

The present study was carried out during a teacher practice curricular unit of a master's course that prepares students to be primary school teachers. It used quantitative methods, predominantly, and its purpose can be classified as action-research, since the results aimed to produce knowledge and to change and transform all the participant actors ([17] Coutinho et al., 2009, p. 363). That is why an action-research project allows teachers to reflect on their own practice, helping the resolution of educational problems through the planning and reformulation of teaching practice ([17] Coutinho et al., 2009). It is also a case study that aims to articulate research and teacher training.

The study was carried out in a class of 25 pupils from a group of the $3^{\text {rd }}$ year of schooling, of both sexes, aged between 7 and 9 years, from a primary school in Lisbon. To achieve the above goals, a one-month intervention plan was designed, addressing knowledge about seismic phenomena and implementing activities to develop appropriate attitudes and behaviours before, during and after earthquakes, promoting a safety culture.

In order to assess the students' knowledge about the seismic phenomenon, and their perception of the seismic risk in the Lisbon region, a questionnaire was used. Through a questionnaire it is possible to ask a set of questions to a sample of individuals and collect relevant information in a short period of time ([18] Quivy \& Campenhoudt, 2003). Furthermore, this technique of data collection allowed a greater systematization of data and comparative analysis thereof at different stages.

The questionnaire had a mixed content, since it included multiple choice questions and open questions. The questions of the questionnaire and their type are listed in Table 1.

The questionnaire was validated by two specialists in Didactics of Science and was piloted on a group of six pupils with similar characteristics to the sample, in order to assess the understanding of the questions, time required for administration and to define the best administration strategies.

The questionnaire was administered in three different stages: before and after the implementation of the intervention plan (pre-test and post-test1); three months after the administration of post-test1 to check the possible persistence of learning (post-test2).

The intervention plan was designed with several sessions where the themes focused on the questionnaire were addressed and included: analysis of leaflets concerning seismic risk from the National Civil Protection Authority; analysis of texts about earthquakes from the collection "Horrible Geography" by Anita Ganeri; viewing of the animation cartoon "When the earth is shaking"; comparison of the Mercalli Scale and the Richter Scale; analysis of the Geological map of the Lisbon region; building of an emergency kit; analysis of the school emergency plan; a school simulacrum exercise.

The questionnaire was scored as if it was a test according to the scientific correction of the answers given by the pupils. Consequently, each pupil had a global score in each of the three tests (pre-test, post-test1, post-test2). Open answers were an object of content analysis, and scored differently, according an answer was correct, partially correct answer or incorrect.

The results were compared using inferential statistics through application of the Statistical Package for the Social Sciences (SPSS). Since the results follow a non-normal distribution, the Wilcoxon test (non 
parametric statistics) was used for two related samples: pre-test versus post-test 1 and pre-test versus post-test2. The level of significance was $p<0,05$.

Table 1. The questions of the questionnaire and their type.

\begin{tabular}{l|l}
\hline \hline Questions & Type \\
\hline I-Knowledge about the seismic phenomenon & \\
\hline 1. What is an earthquake? & Multiple choice \\
\hline 2. How long does an earthquake last? & Multiple choice \\
\hline 3. Can we measure an earthquake magnitude? If yes, how? & Multiple choice, Open \\
\hline 4. Can we know the exact date and time of occurrence of an earthquake? If yes, how? & Multiple choice, Open \\
\hline 5. Can we prevent the effects of an earthquake? If yes, how? & Multiple choice, Open \\
\hline II-Perception of risk seismic in the Lisbon region & \\
\hline 6. How do you assess the seismic risk of the Lisbon region? & Multiple choice \\
\hline 7. If an earthquake occurs in Lisbon, are some places more dangerous than others? Is & Multiple choice, Open \\
yes, say which are they? & \\
\hline 8. Has the Lisbon region been destroyed by an earthquake? If yes, when did it happen? & Multiple choice, Open \\
\hline III- Security at school & \\
\hline 9. In the event of an earthquake do you think your classroom is a safe place? Justify. & Multiple choice, Open \\
\hline 10. What should you do in the event of an earthquake? & Multiple choice \\
\hline $\begin{array}{l}\text { 11. In the event of an earthquake, do you know where the meeting point is in your } \\
\text { school? If yes, say where is it? }\end{array}$ & Multiple choice, Open \\
\hline \hline
\end{tabular}

To respect the privacy and confidentiality of the participants, their names are not mentioned during the research results. Thus, whenever the pupils' ideas are transcribed as examples given in the open questions, they are coded with a letter, $\mathrm{P}$, and assigned a number ranging from 1 to 25 , precisely the number of participants (e.g. P13).

\section{RESULTS}

\subsection{Analysis of the answers to the different questions}

In the pre-test, the pupils revealed little knowledge and several incorrect ideas about the seismic phenomenon: 14 out of the 25 pupils considered that an earthquake resulted from the release of matter or gases accumulated in the earth's crust; 20 affirmed that an earthquake can last a long time and eight considered that it was possible to know in advance the exact day and hour it will happen. Comparatively, in the post-test 1 and the post-test 2 the 25 pupils reported correctly that an earthquake resulted from the release of energy accumulated in the earth's crust, it was a phenomenon of short duration and that it was not possible to know the exact date and time of its occurrence.

Concerning the question about the possibility of measuring the magnitude of an earthquake, in the pre-test only one student mentioned that possibility, explaining that "there are scales that can be used; a very large earthquake can be valued as 8,6 or 9,5 "(P13). After the intervention plan, the results from the post-test 1 and the post-test 2 were much better. Even knowing that the majority of the answers were, in both tests, incomplete, there was a great improvement. An example of this type of incomplete answer was the following: "there is a machine called a seismograph" (P18). Much less frequent were the totally correct answers, such as the following: "It can be measured with machines that are called seismographs and by using the Richter scale" (P8). The number of totally correct answers also decreased in the post-test2, which shows that not all knowledge has lasted so effectively in time.

Regarding the predictability of an earthquake, in the pre-test, all the pupils said they did not know if it was possible or not. This situation changed completely in both the following tests, with all pupils affirming its impossibility. A similar result occurred in the question about the possibility of doing something to prevent an earthquake. None of the pupils knew what to do or if it was possible to do anything; after the sessions of the intervention plan the more frequent answers in post-test 1 and post- 
test2 mentioned the possibility of preparing an emergency kit. Even so, this common answer was considered incomplete, since during the sessions the idea of the necessity of also having an emergency plan was debated.

Regarding the seismic risk of the Lisbon region, in the pre-test, all the students considered that it was low or did not know how to evaluate it or if there were different areas with a different seismic risk. In post-test 1 and in post-test2, 14 pupils correctly answered this question, assessing the seismic risk in the Lisbon region as medium to high. After the analysis of the geological map of the region of Lisbon, the majority of pupils were unable to identify the areas of Lisbon of greater and smaller seismic risk. However, this failure can be related to the difficulty of the task of analyzing the geological map and of mentioning concrete names of different Lisbon areas. Therefore, we considered that the task was too demanding for the pupils' age, which justifies their lack of success.

Regarding the knowledge of the destruction of Lisbon by an earthquake, in the pre-test, no student knew the date of the earthquake that destroyed Lisbon, but they knew that it had happened "many years ago" (P24) or "a long time ago "(P14). In post-test 1 and post-test 2, most of the students, respectively 22 and 21 , were able to respond to this question; although not all of them were able to indicate the correct date, 1755.

Concerning seismic prevention at school, in the pre-test, pupils tend to consider their classroom unsafe, since "it is an enclosed space" (P1), "there are heavy lights on the ceiling and there is no safe shelter"(P3)," there are things in the room that can hurt us "(P9) or" because it is not a high place"(P24). During the intervention plan, the classroom was analyzed carefully and the pupils' opinions changed. In post-test 1 and post-test 2, about half of the students considered the classroom a safe place, "because there are tables that can protect us" (P2). In post-test 1, one of the pupils also noted that "there is furniture without heavy things on top" (P8) an idea not repeated in post-test 2. Finally, in the pre-test, the majority of the pupils responded that they knew where the school meeting point was. However, they indicated a wrong location. This did not happen in the post-test 1 and the post-test 2 for all pupils.

\subsection{Statistical comparison of overall results}

The comparison of the means of the global scores obtained by the pupils was carried out between the results of the pre-test and the post-test 1 and, subsequently, between the pre-test and the post-test 2 , using the Wilcoxon test $(Z)$ (Table 2).

Table 2. Statistical comparison of the overall results between pre-test and post-test1 and between pre-test and post-test2 using the Wilcoxon test (Z).

\begin{tabular}{l|c|c|c}
\hline & Mean & Z & p. \\
\hline Pre-test & 2,68 & $-4,391$ & 0,001 \\
\hline Post-test1 & 9,68 & & \\
\hline Pre-test & 2,68 & $-4,389$ & 0,001 \\
\hline Post-test2 & 9,4 & & \\
\hline
\end{tabular}

From the use of the Wilcoxon $(Z)$ test, a value of $p<0.001$ was obtained, either between the results of the pre-test and the post-test1, and between the results of the pre-test and the post-test2. This means that the differences were statistically significant. Thus, it can be stated that the intervention plan was effective in improving students' knowledge about the seismic phenomenon and that this knowledge persisted over time.

\section{CONCLUSIONS}

The present research allows us to conclude that the participants did not know much about the seismic phenomenon in general and about the seismic risk of the Lisbon region before the development of the intervention plan. After the intervention, the pupils increased their scientific knowledge about the seismic phenomenon and it lasted over time, evidence that the main objectives of the study were achieved. 
However, knowledge has not improved in all the addressed dimensions. The greatest failure was pupils' difficulty in understanding and identifying different areas of Lisbon with a different degree of seismic danger, which shows the need to rethink new strategies and resources in future interventions to approach this theme, more adequate to the children's age.

The present study also helped to develop appropriate attitudes and behaviours before, during and after an earthquake, increasing a culture of safety at school and at home, as children have become informed and aware citizens about seismic risk, knowing how to minimize in the future. For that, the practical sessions in the classroom and in the school playground were essential.

The intervention plan also helped understanding that seismic risk in the city of Lisbon is real, although the seismic pattern is characterized by long periods of low seismicity interrupted by major earthquakes. But, children became more aware that this pattern of occurrence does not remove the need to implement prevention measures at school or at home.

This pattern of seismicity occurs in distinct regions of the planet, such as in several areas of the Mediterranean region ([19] Purcaru \& Berckhemer, 1982), in the region of S. Francisco, California ([20] Bufe \& Varnes, 1993), or in the Himalayan region ([21] Avouac, 2003). Therefore, it is considered that this case study may help others to outline intervention plans that draw attention to the danger of seismic risk. Moreover, earthquakes are unpredictable and can occur during school time, which increases the school's responsibility for the need to address this issue.

\section{ACKNOWLEDGEMENTS}

This study is part of a project entitled "Research in didactics of science: implications for the improvement of teaching practices" and is funded by the Interdisciplinary Center of Educational Studies (Centro Interdisciplinar de Estudos Educacionais - CIED) based in the Lisbon Higher School of Education, Portugal.

\section{REFERENCES}

[1] B. Fischhoff \& J. Kadvany, Risk. A Very Short Introduction. Oxford: Oxford University Press, 2011.

[2] A. Saúde, E. Costa, J. J. Fernandes, M., J. Esteves, M. L., Amaral, P. Almeida, \& T. L. André. Referencial de Educação para o Risco - Educação Pré-Escolar, Ensino Básico $\left(1 .^{\circ}, 2 .^{\circ}\right.$ e $3 .^{\circ}$ ciclos) e Ensino Secundário. Lisboa: Ministério da Educação e Ciência, 2015.

[3] B. Wisner, P. Blaikie, T. Cannon, \& I. Davis, At Risk. Natural hazards, People's Vulnerability and Disasters $\left(2^{\text {nd }}\right.$ ed. $)$. London, Routledge, 2004.

[4] A. Smolka, "Natural disasters and the challenge of extreme events: risk management from an insurance perspective," Philosophical Transactions of the Royal Society, vol. 364, pp. 21472165, 2006.

[5] L. S. Hill, R. S. Sparks, \&, J. C. Rougier, "Risk assessment and uncertainty in natural hazards" in Risk and Uncertainty Assessment for natural Hazards (J. Rougier, S. Sparks, L. Hill eds.), pp. 1-18, Cambridge: Cambridge University Press, 2013.

[6] M. Lima, "Tragédia, risco e controlo: uma releitura psico-social dos testemunhos do terramoto de 1755," Análise Social, vol. XLIII, no. 1, pp. 7-28, 2008.

[7] R. Geller, "Earthquake prediction: a critical review," Geophys. J. Int., vol. 131, pp. 425-450, 1997.

[8] L. J. Axelrod, T. Mcdaniels, \& P. Slovic, "Perceptions of ecological risk from natural hazards." Journal of Risk Research, vol. 2, no. 1, pp. 31-53, 1999.

[9] E. Vila-Nova, Educar para a Protecção Civil - Projectos para a Área-Escola e Actividades de Complemento Curricular. Lisboa: Texto Editora, 1997.

[10] J. Borges, A. Fitas, M. Bezzeghoud, \& P. Teves-Costa, "Seismotectonics of Portugal and its adjacent Atlantic area," Tectonophysics, vol. 337, pp. 373-387, 2001. 
[11] J. Birkmann, K. Von Teichman, T. Welle, M. Gozález, \& M. Olabarrieta, "O risco não percepcionado para as zonas costeiras da Europa: Os tsunamis e a vulnerabilidade de Cádis, Espanha," Revista Crítica de Ciências Sociais, vol. 93, pp. 129-165, 2011.

[12] M. Costa, \& J. Fonseca, "Sismicidade histórica em Portugal no período medieval," in Atas do 7. ${ }^{\circ}$ Congresso Nacional de Sismologia e Engenharia Sísmica, Porto, 2007, Retrieved from: https://drive.google.com/file/d/1A-DV-7jO_-II8tUXtCM3ayiTFBTTjIT0/view?usp=sharing

[13] A. Ribeiro, "O sismo de 1/11/1755: significado geodinâmico" in O Grande Terramoto de Lisboa. Ficar Diferente (H. Buescu, G. Cordeiro eds.), pp. 77-88, Lisboa: Gradiva, 2005.

[14] A. O. Tavares, J. M, Mendes, \& E. Basto, "Percepção dos riscos naturais e tecnológicos, confiança institucional e preparação para situações de emergência: O caso de Portugal continental." Revista Crítica de Ciências Sociais, vol. 93, pp. 167-193, 2011.

[15] D. Téllez Alarcia, "El impacto del terremoto de Lisboa en España," In O Terramoto de 1755: Impactos históricos. (A. Araújo, J. Cardoso, N. Monteiro, W. Rossa, J. Serrão eds.), pp. 77-95, Lisboa: Livros Horizonte, 2007.

[16] United Nations, "World Conference on Disaster Reduction. Hyogo framework for action 20052015: building the resilience of nations and communities to disasters," Hyogo (Japan), 2005, Retrieved from: https://www.unisdr.org/2005/wcdr/wcdr-index.htm

[17] C. P. Coutinho, A. Sousa, A. Dias, F. Bessa, M. J. Ferreira, \& S. Vieira (2009), "InvestigaçãoAcção: metodologia preferencial nas práticas educativas," Psicologia, Educação e Cultura, vol. XIII, no. 2, pp. 355-380, 2009.

[18] R. Quivy, \& L. Campenhoudt, Manual de Investigação em Ciências Sociais. Lisboa: Gradiva, 2003.

[19] G. Purcaru, \& H. Berckhemer, "Regularity patterns and zones of seismic potential for future large earthquakes in the Mediterranean region," Tecronophysics, vol. 85, pp. 1-30, 1982.

[20] C. Bufe, \& D. Varnes, "Predictive modeling of the seismic cycle of the Greater San Francisco Bay Region," Journal of Geophysical Research: Solid Earth, vol. 98, no. B6, pp. 9871-9883, 1993.

[21] J. Avouac, "Mountain building, erosion, and the seismic cycle in the Nepal Himalaya," Advances in geophysics, vol. 46, pp. 1-80, 2003. 